IZA DP No. 9216

Can I Have Permission to Leave the House?

Return Migration and the Transfer of Gender Norms

Michele Tuccio

Jackline Wahba

July 2015 


\title{
Can I Have Permission to Leave the House? Return Migration and the Transfer of Gender Norms
}

\author{
Michele Tuccio \\ University of Southampton \\ Jackline Wahba \\ University of Southampton \\ and IZA
}
Discussion Paper No. 9216
July 2015

IZA

P.O. Box 7240

53072 Bonn

Germany

Phone: +49-228-3894-0

Fax: +49-228-3894-180

E-mail: iza@iza.org

Any opinions expressed here are those of the author(s) and not those of IZA. Research published in this series may include views on policy, but the institute itself takes no institutional policy positions. The IZA research network is committed to the IZA Guiding Principles of Research Integrity.

The Institute for the Study of Labor (IZA) in Bonn is a local and virtual international research center and a place of communication between science, politics and business. IZA is an independent nonprofit organization supported by Deutsche Post Foundation. The center is associated with the University of Bonn and offers a stimulating research environment through its international network, workshops and conferences, data service, project support, research visits and doctoral program. IZA engages in (i) original and internationally competitive research in all fields of labor economics, (ii) development of policy concepts, and (iii) dissemination of research results and concepts to the interested public.

IZA Discussion Papers often represent preliminary work and are circulated to encourage discussion. Citation of such a paper should account for its provisional character. A revised version may be available directly from the author. 


\title{
ABSTRACT
}

\section{Can I Have Permission to Leave the House? Return Migration and the Transfer of Gender Norms*}

\begin{abstract}
Does international return migration transfer gender norms? Focusing on Jordan, an Arab country where discrimination against women and emigration rates are high, this paper exploits unique data in which detailed information on female empowerment allows us to construct several measures of discriminatory social norms in Jordan on the role of women, female freedom of mobility, and female decision-making power. Controlling for both emigration and return migration selections, we find that women with a returnee family member are more likely to have internalized discriminatory gender norms than women in households with no migration experience. Further analysis shows that results are driven by returnees from conservative Arab countries, suggesting a transfer of negative norms from highly discriminatory destinations. We also show the implications of our results beyond perceptions for several economic and development outcomes, such as female labour force participation, education and fertility.
\end{abstract}

\section{JEL Classification: F22, J16, O15, O53}

Keywords: international return migration, gender inequality, transfer of norms

Corresponding author:

Michele Tuccio

Economics Department

School of Social Sciences

University of Southampton

Southampton, SO17 1BJ

United Kingdom

E-mail:m.tuccio@soton.ac.uk

\footnotetext{
* We would like to thank Simone Bertoli, Hector Calvo Pardo, Raj Chowdury, Corrado Giulietti, Martin Guzi, Emmanouil Mentzakis, Maryam Naghsh Nejad, Mariola Pytlikova, Hillel Rapoport, Ibrahim Sirkeci, Mirco Tonin, and Yves Zenou for helpful discussion. We are also grateful to seminar participants in Washington DC, Oxford, Southampton, Hannover, Palermo, and Brno for useful comments. Michele Tuccio acknowledges financial support from the Economic and Social Research Council (ESRC). Any remaining errors are ours.
} 


\section{Introduction}

The past few decades have witnessed an increasing awareness of the need to achieve gender equality as a necessary step for greater economic development (see for example Duflo (2012) for a survey on the relationship between female empowerment and economic development). Social institutions and norms frame the gender roles at the roots of a society and the distribution of power between men and women in the household and in the economic and political landscapes Alesina, Giuliano and Nunn (2013)). If these social norms deprive women of their autonomy and capabilities, then a gender gap is created between men's and women's opportunities, and consequently between their respective outcomes (Field, Jayachandran and Pande (2010)).

Exposure to different practices within a country has been proved to be a powerful tool to modify underlying gender norms (Beaman et al. (2009); Meyersson (2014)). This paper demonstrates that, through exposure, international migration may also act as a channel of norms transmission. In fact, ideas and behaviors in destination countries influence the set of norms that migrants have acquired at home, assimilating their beliefs to those of the natives. When migrants visit or return to their origin countries, they bring back the newly acquired norms and those may spread around their communities.

This paper presents a three-fold contribution to the economic literature. While political accountability and fertility norms have been found to be promoted in origin countries by international migrants (Spilimbergo (2009); Batista and Vicente (2011); Beine, Docquier and Schiff (2013); Bertoli and Marchetta (2015)), whether migration modifies gender norms is still an unanswered question. This paper therefore fills the existing gap by studying whether return migration acts as a channel of norms transmission and reduces gender discrimination in social norms at home.

Secondly, this paper is among the first ones to construct a composite index of discriminatory gender social norms at micro level $]^{1}$ Whilst previous works concen-

\footnotetext{
${ }^{1} \mathrm{~A}$ recent exception is the work by Assaad, Hendy and Yassine (2014).
} 
trated on outcomes variables, such as education or employment status, we argue that gender gaps in opportunities are indeed at the root of the consequent inequalities in outcomes. Hence, focusing on discriminatory norms and social institutions is key to understanding gender inequality.

A further contribution of the present study is to emphasize the importance of controlling for both selection into emigration and selection into return migration when comparing returnee and non-migrant households. We demonstrate that estimates are biased if double selectivity is not taken into account.

We focus on the case of Jordan, a Middle-Eastern, non-oil middle-income economy where both gender inequality and emigration rates are high. Our analysis is based on the recently-released "Jordan Labor Market Panel Survey" (JLMPS), a nationally representative household survey of more than 5,100 households and about 25,000 individuals in 2010 .

Although women's educational attainment gradually reached the level of their male counterparts, Jordan has still one of the lowest female labour force participation rates in the world at 15 percent in 2010 (Assaad, Hendy and Yassine (2014)). The World Bank (2005) gender assessment report confirms that women's economic role in Jordan does not correspond to the pattern seen in similar middle-income countries. De facto, societal and familial pressures limit women's greater position in the economy. For example, while entering certain public spaces, such as administrative offices, without male presence is considered unacceptable (OECD (2014)), some women's movements may still be restricted on a day-to-day basis: 14.4 percent of women questioned in the 2007 DHS survey reported that they needed their husbands' permission to visit their own family or relatives.

In addition, women are still not equal to men before the law. For instance, Kelly (2010) reports that, under the Personal Status Law, all single women (whether divorced, widowed, or never married) under 30 are considered to be legal minors, and are under the guardianship of a male relative. Discriminatory norms are reflected in Jordan's low placement in human rights indices: under the 2011 Human Development Index (HDI), Jordan is ranked in 95th place (out of 187 countries), with a 
score of 0.698 . The Gender Inequality Index value is 0.456 placing it at 83 out of 146 countries, while it is ranked 117th in the 2011 Global Gender Gap Index.

At the same time, Jordan is a labor exporter economy, with a migrant population ratio reaching 11.2 percent in 2005 (Xu and Ratha (2008)). This is much higher than the 3.3 percent emigrant population average share for middle-income countries. More importantly, as pointed out by Wahba (2014), almost every one in 10 households in Jordan had a return migrant in 2010 as the majority of migration is temporary and destined to neighboring Arab countries.

This paper aims to explain the aforementioned stylized facts by examining the role of return migration and its impact on gender norms. Results show that return migrants transfer discriminatory norms from highly unequal destination countries, which widen already existent gender gaps in Jordan. Our findings confirm that social norms are a key determinant of the failure of convergence in labour market outcomes, perpetuating extremely low female labour force participation in Jordan.

The remainder of the paper is structured as follows: section 2 provides a brief review of the current scholarly understanding of the "transfer of norms"-migration nexus. Section 3 introduces data, summary statistics, and the construction of the composite indices of gender norms. Section 4 discussed the empirical approach and econometric framework, whilst the estimation results are provided in section 5 . Section 6 concludes.

\section{Migration-Induced Transfer of Norms}

While the analysis of the determinants of international migration has received great attention over the last years, a growing strand of the literature is now focusing on the possible externalities that migration may bear on sending areas. The so-called "transfer of norms" literature assumes that international migration drives institutional changes in origin countries. Essentially, migrants living in a foreign country and returnees stream new ideas and narratives to their community members, which consequently shift the social norms and institutions in place at home. 
Economic studies on the "transfer of norms"-migration nexus have started to grow after the work of Spilimbergo (2009) on democracy and foreign education. Using data for 183 countries over the period 1960 to 2005, he finds that foreigneducated individuals play a role in fostering democracy in their home countries. Similarly, Batista and Vicente (2011) use a simple voting experiment in Cape Verde to demonstrate that international migration experiences promote better institutions at home by boosting demand for political accountability. Other recent contributions use electoral data from Moldova (Omar Mahmoud et al. (2014)) and Mali (Chauvet and Mercier (2014)) to estimate a migration-induced transfer of political norms.

Fertility choices have also attracted much attention over the last few years. In particular, Beine, Docquier and Schiff (2013) argue that, through the transfer of norms, migration from high-fertility sending countries to low-fertility destination countries reduces fertility in the former. Conversely, Bertoli and Marchetta (2015) demonstrate that Egyptian married couples where the husband has a past migration experience in another Arab country have a significantly larger number of children than stayers.

Much less attention has been given to the relationship between migration and gender inequality in origin countries. At macro level, Lodigiani and Salomone (2012) investigate the effect of international migration on the parliamentary participation of left-behind women. They show that total international migration to countries where the share of female parliamentary seats is higher increased source country female political voice between 1960 and 2000. The authors argue that such results may be linked to the informational role of international migrants, who can transfer foreign values, reshape attitudes and create new norms about women in the origin country. A broader concept of gender inequality is adopted by Ferrant and Tuccio (2015), which focuses on overall discrimination against women in developing countries using the Social Institutions and Gender Index of the OECD Development Centre. Their crosscountry analysis of bilateral South-South migration flows finds that migration may either entrench or challenge gender inequality according to the level of discriminatory social institutions in the host country. 
To our knowledge, micro-economic evidence on the impact of international migration, and in particular return migration, on female empowerment is rather sparse. Although there are a few sociological works analyzing the role of migration on gender equality, most studies look at the position of female stayers when their male partners are currently abroad. Hence, regardless of the sign, the effect can be due to a change in household composition, with left-behind wives taking up the role of the absent husbands. However, the change in responsibilities and decision-making power among women can be temporary in nature, since men may assume their traditional, patriarchal roles as soon as they return (De Haas and Van Rooij (2010)). The present paper is therefore the first economic study to analyze return migrants and their effect on discriminatory gender norms.

\section{Migration and Gender Norms in Jordan}

\subsection{Data and Descriptive Statistics}

International migration has played a key role in shaping Jordan's economic and social landscapes. Since the 1973 increase in international oil prices, large flows of Jordanians emigrated towards the neighboring GCC states. According to the national Ministry of Labor, 140,722 Jordanians were still residing in oil-producing countries in 2009, 39 percent of whom in the United Arab Emirates, 36 percent in Saudi Arabia and 13 percent in Kuwait. Return migration is also an important feature of Jordanian society, with approximately 11 percent of the households having a returnee among their members (Wahba (2014)). Looking at the characteristics of returnees by destination suggests that emigrants to Arab countries have similar education levels to those who went to the West: roughly 40 percent of Jordanian emigrants to both destinations have secondary education or higher (Wahba (2014)).

The analysis of this paper is based on the recently-released "Jordan Labor Market Panel Survey" (JLMPS), which was administered by the Economic Research Forum (ERF), the Department of Statistics in Jordan (DoS) and the National Centre for 
Human Resources Development (NCHRD) in the period from December 2009 to June 2010. The JLPMS is a nationally representative data covering about 5,100 households and 25,000 individuals and has rich information on demographic characteristics and labour market experiences.

Despite being the initial wave of what is to be a longitudinal survey, the JLMP 2010 contains a number of distinctive features which are key for the present study. Firstly, retrospective questions on labour and residence mobility allow us to identify return migrants. Secondly, a unique characteristic of this survey is that it provides information on current migrants, including education and employment history, year of migration and destination country which allows us to control for selection into emigration 2 Lastly, and a real peculiarity among labour market surveys, the JLMP includes important information about women's status in the society. Specific questions on the self-perceived role of women, freedom of mobility and the extent to which women can take decisions in their families can be used in order to proxy for the long-lasting codes of conduct, norms, traditions, informal laws that might contribute to gender inequalities in all spheres of life.

Only 5 percent of returnees in our sample went to non-Arab countries $]^{3}$ whilst the remaining 95 percent migrated towards Arab countries. For this reason, we restrict our analysis to migrants towards the Arab region.

Table 1 compares individual characteristics of women with a returnee among their family members and women from non-migrant households. Data confirms the existence of a paradox in Jordanian society: more than 40 percent of women have a secondary or higher degree, but only 14 percent is formally employed. These figures suggest that underlying social norms on what is deemed acceptable for women limit their employment at full capacity. Approximately one in every five women is married

\footnotetext{
${ }^{2} \mathrm{~A}$ common caveat of migration data is the lack of information on households which have emigrated in their entirety, and therefore are not interviewed at the time of the survey. However, in the Jordan case the eventual bias may be considered rather small, since migration towards Gulf countries is mostly temporary in nature (David and Marouani (2013)), as also supported by the fact that almost 38 percent of current migrants in our sample has left Jordan in the last two years. At the same time, more than 80 percent of current migrants have visited the left-behind household in the last two years, assuring the reliability of the information provided by the interviewees.

${ }^{3}$ Non-Arab countries are mainly Europe, the US, Canada and Australia.
} 
to a family member, reflecting the role of norms and informal institutions in Jordan. Interestingly, women with a returnee are on average older and more educated than those in households with non-migrant, and also their mothers have achieved greater educational attainments. Moreover, having a returnee is often linked with a greater probability of living in cities.

\subsection{Construction of Composite Indicators}

Most previous studies constructed cross-country measures of broad concepts of gender inequality, including outcome variables such as educational and employment status, poverty and political participation (Ferrant (2014)). There is very little literature on the construction of composite indicators of discrimination against women at micro level, and even scarcer literature focusing on discriminatory social norms rather than on outcomes (a recent exception is Assaad, Nazier and Ramadan (2014)).

However, the use of household and labour market surveys often provides categorical and binary questions that need to be aggregated into composite indices in order to have an overall view of the dimensions under analysis. We exploit 3 sets of variables included in the JLMPS on gender norms, administered to all females in the age group 15-60.

Our benchmark analysis on the self-perceived role of women (RWI) will be based on 10 questions on what women think should be their role in the society. Queries involve whether girls should be treated equally to boys, whether female employment should be encouraged as well as female education, and whether women should get leadership positions in the society. We will also use two additional measures of gender norms. The first set of questions deals with women's freedom of mobility (FMI): variables on whether women need permission to move are exploited to have a sense of the freedom of mobility at household level. Specifically, women are asked if they need prior permission to go to the local market, to the doctor or to visit friends and relatives. Secondly, we make use of 9 variables on female decisionmaking (DMPI) to understand the extent of women's bargaining power and agency 
within the family. Questions include who has the final say on making household purchases, getting medical treatment and sending children to school. We argue that overall these three measures, 23 variables, effectively represent the underlying gender norms in Jordanian society.

Several approaches can be adopted to aggregate our variables into composite indicators of gender equality in social norms. Equal weights have been extensively used for their simplicity and apparent objectivity. They are often preferred since there may be no obvious reason for valuing one variable more or less than the others. In our case, although singly the variables had a categorical response, they have been re-coded in order to take binary value. The average mean of the respectively 10 , 4 and 9 variables has then been calculated in order to have 3 different measures of gender norms in Jordan. The proposed index is transparent and easy to understand: it can take values from 0 , corresponding to discriminatory social norms, to 1 , meaning complete gender equality.

On the other hand, average mean implicitly assigns greater weights to the variables with larger variance and higher correlation with each other (Ferrant (2014)). Since the imposition of numeric equality is completely arbitrary, the use of statistical procedures to determine weights should be favoured (Filmer and Pritchett (2001)). Principal Components Analysis (PCA) is one of the most common weighting techniques, which extracts from a group of variables those orthogonal linear combinations that size the common information most accurately. Essentially, gender equality can be seen as complex unobserved phenomenon that we want to estimate using a set of observed proxies. The goal of PCA is to aggregate the variables that we assume can best describe gender equality in such way that they represent successfully the latent complex index. Weight determined on the basis of PCA represents the relative contribution made by the variables to the variance of the composite index. Greater weights are assigned to variables which contribute to larger shares of variation. The advantage of this methodology is to estimate the set of weights that explains the largest variation in the original variables.

Nonetheless, recent studies have emphasized that Principal Component Analysis 
(PCA) was originally designed for continuous variables, whilst Multiple Correspondence Analysis (MCA) should be preferred to analyze qualitative, categorical and binary variables $($ Ferrant $(2014))$. Conversely to PCA, which estimates the absolute weight of each component, MCA studies their relative frequencies.

Constructing composite indicators using MCA involves building an indicator matrix of 1 and 0 values which describes the various gender norms under analysis. Importantly, every variable is disaggregated into mutually exclusive and exhaustive dummies, one for each category. In other words, each woman (or row) will have 1 in one and only one category (or column), and 0 in all the others. Let's consider a matrix with $Q$ questions, $C_{q}$ categories for question $q$, and $C$ total categories. The main difference between PCA and MCA is that in the latter every row has to answer " 1 " to one category in each question, that is, the categories represent all possible answers for the given question $q$. Consequently, each row in the matrix must have a total of $Q$. In the former, instead, the redundant category for each question is omitted (Booysen et al. (2008)).

For the aforementioned reasons, we undertake our analysis using MCA, but we test the robustness of our results using both PCA and equal weights. Our composite indices of gender norms are given by:

$$
Y_{i}^{j}=A_{i 1} W_{1}^{j}+A_{i 2} W_{2}^{j}+\ldots+A_{i q} W_{q}^{j}
$$

where $Y_{i}^{j}$ is the value of composite index $Y$ (i.e. Role of Women Index, RWI; Freedom of Mobility Index, FMI; and Decision-Making Power Index, DMPI) for individual $i$ using the weighting technique $j$ (namely, MCA, PCA and equal weights), $A_{i q}$ is the answer of individual $i$ to question $q$ and $W_{q}^{j}$ is the weight obtained using the $j$ methodology applied to question $q .4$

\footnotetext{
${ }^{4}$ Table 13 in Appendix lists the 10 variables that are used to construct the Role of Women Index (RWI) and the respective weights using PCA, MCA and average mean. Greater weights indicate higher level of female empowerment. Looking at the MCA results, it's worth to note that those components which reflect greater female empowerment contribute positively to the gender equality index, while components that reflect discriminatory social norms contribute negatively. Similarly, Tables 14 and 15 present the variables and the correspondent weights for the Freedom of Mobility Index (FMI) and for the Decision-Making Power Index (DMPI).
} 


\section{Empirical Framework}

We use the three constructed composite indicators $Y_{i}^{j}$ (Role of Women Index, RWI; Freedom of Mobility Index, FMI; and Decision-Making Power Index, DMPI) through the weighting technique $j$ as our dependent variable in order to estimate the causal effect of international return migration on discriminatory social norms in Jordan. The regression specification is:

$$
Y_{i}^{j}=\alpha_{0}+\alpha_{1} R_{i}+\alpha_{2} X_{i}+\epsilon_{i}
$$

$Y_{i}^{j}$ is the gender norms index: $R W I_{i}$ is the self-perceived role of women by individual female $i$, where 0 means high discrimination against women and 1 implies perfect gender equality. $F M I_{i}$ is the self-perceived freedom of mobility by individual female $i$, where 0 means no freedom and 1 implies perfect freedom. $D M P I_{i}$ is the self-perceived decision making power by individual female $i$, where 0 means no power and 1 implies perfect power. $R_{i}$ is the return migration variable, a dummy being 1 if the individual has at least an international returnee member from an Arab country within the household. $X_{i}$ is a vector of individual female's characteristics, including age, age squared, marital and employment status, educational attainment, mother's education, a dummy for having at least one child, a dummy for living in a rural area, a dummy for being married to a relative, and governorate dummies. $\epsilon_{i}$ is a zero-mean error term.

Selection of migrants is an important concern, since individuals moving across borders are not randomly drawn from the Jordanian population, but they may be self-selected on the basis of unobservable characteristics. For example, open-minded people may be more likely to engage in international migration as well as bear more gender-equal attitudes towards women. At the same time, return migrants might also be a non-random group amongst migrants (Wahba (2015)). For instance, unsuccesful migration experiences can affect simultaneously the likelihood of returning back home and negative attitudes and behaviours against left-behind women. Therefore, in order to control for this double selectivity and correctly identify our full model, 
two valid exclusion restrictions for the emigration and return decisions are needed.

For the selection into emigration, we follow Wahba and Zenou (2012) and use historical real oil prices. This variable has a substantial influence on the scale of emigration towards oil-producing countries which adopt employer-driven immigration systems and respond to fluctuations in local economic conditions. While real price of oil could affect migration flows by attracting more migrants towards oil-producing countries, it has no effect on the level of gender inequality in Jordan. Specifically, we adopt average oil prices for when the potential migrant individual was 20 years old, arguing that this is the time in which individuals enter in the labour market. In fact, military conscription at the age of 18 was compulsory for all boys with a minimum term of 2 years, until 1999, when it still became voluntary for 2 years. We confirm our hypothesis by exploiting a variable on the age at first job included in the JLMPS. Indeed, the average age at first job in our sample is exactly 20 years old. Age of current migrants, however, is not provided in the JLMPS. Hence for them we take oil prices for the year of first cross-border movement.

Figure 1 shows the correlation between real oil price and the number of Jordanian emigrants by year. As robustness, we also adopt oil prices for when the potential migrant was 24 years old, which is the normal age of the end of university in Jordan.

It is worth to note that our instrument would be invalid if variations in real oil prices affected also the employment of Jordanian women, and consequently female empowerment in the society. However, we can safely reject this hypothesis, since Jordan is a non-oil country. Nonetheless, concerns of violation of the exclusion restriction might still remain if there is a strong serial correlation between the evolution of real oil prices and gender norms over time. In particular, a potential caveat may be the simultaneous presence of the declining trend in emigrants seen in the 1980s and 1990s and an overall declining trend of discriminatory norms over time due to a general advancement of the society. However, analyzing Figure 1, we can reject this hypothesis too, since we do estimate an increase in migration flows again in the 2000s, caused by rising real oil prices. A last potential threat to the validity of this exclusion restriction is linked to the fact that historical real oil prices might 
have a direct impact on migration duration and hence return migration. However, it is well-documented that Jordanian emigration towards the neighboring Gulf is temporary in nature (David and Marouani (2013)). Moreover, a recent study by McKenzie, Theoharides and Yang (2014) finds that shocks in destination country GDP have no effect on the duration of the migration experience of Filipino migrants (a large proportion of which works in the Gulf).

For the selection into return migration, we construct a dummy including several exogenous shocks that induced Jordanian emigrants to come back to their homes. Firstly, we consider the 1967 Arab-Israeli war, which was fought in only six days by Israel and its neighboring countries, but led to thousands of displaced individuals from the war zones. Secondly, we take into account the First Lebanon War of 1982, where thousands of both civilians and military forces died, pushing many labour immigrants to return to their origin countries. Iraq's invasion of Kuwait, instead, led to the First Gulf War in 1990-1991, which made inevitable a huge counter-diaspora of migrants towards their home communities. Finally, the Iraq war in 2003 which has lead to the outflows of migrants. Worthy of note is the fact that these shocks did not affect the probability of emigration, but only the destination of migration.

Exploiting the unique information on both returnees and current migrants included in the JLMPS, we are able to estimate the following selections equations:

$$
\begin{aligned}
& M_{k}=\beta_{0}+\beta_{1} O_{k}+\beta_{2} Z_{k}+\mu_{k} \\
& R_{k}=\gamma_{0}+\gamma_{1} S_{k}+\gamma_{2} C_{k}+n_{k}
\end{aligned}
$$

In equation 3, $M_{k}$ is the probability of individual $k$ being an emigrant, whilst $O_{k}$ is the international oil price variable. Controls $Z_{i}$ for the potential migrants and their household include the level of education, the governorate of interview and the employment status before migration. In the return migration equation (4), $R_{k}$ is the probability of being a return migrant, conditional on being an emigrant, and $S_{k}$ represents the shock variable, constructed as previously explained. Controls $C_{i}$ include 
the migrant's age, age squared, educational attainment, regional characteristics and the destination of the migrants.

The three equations above (eq. 22 - eq. 4) are estimated simultaneously using Conditional Mixed Process (CMP). Our recursive system is made up of 2 Heckman selections and we use limited-information maximum likelihood (LIML). CMP allows the estimation of a multi-equation mixed system in a Seemingly Unrelated Regressions (SUR) framework, where regressors seem unrelated, although their errors can be correlated. As underlined by Roodman (2011), in a SUR set-up we can estimate parameters equation-by-equation, but their simultaneous assessment is more efficient since it considers the full covariance structure.

\section{$5 \quad$ Econometric Results}

\subsection{Return migration and gender norms}

Our benchmark results are provided in Table 2. When selection issues are not accounted for, having a returnee in the household seems to have a negative, albeit insignificant, impact on the self-perceived role of women. However, the negative coefficient of return migration becomes statistically significant once we control for selections into emigration and return migration. This stresses the importance of taking into consideration not only the fact that emigrants are not a random sample of the population, but also that those migrants who return home are also selected on the basis of unobservables 5

Our dependent variable is a composite index which aggregates together several indicators on women's perception of their own status in the society compared to men. A value towards 0 implies that women think their position should be greatly different than the one of men, whilst a value towards 1 means that women acknowledge the importance of equality across genders. Overall, our findings in column (3) show that

\footnotetext{
${ }^{5}$ Table 16 in Appendix estimate a simple Heckman model with sample selection for emigration. Results suggest the need for correcting for selection, as well as the validity of our exclusion restriction.
} 
women with returnee family members are less likely to believe that men and women should have an equal position in the society. This indeed suggests a transfer of discriminatory norms from destination countries, a possibility that we will examine further below.

It is important to note that international real oil price is a good predictor of the probability of having emigrated in that specific year, while our shock dummy efficiently predicts the likelihood of returning home.6 ${ }^{6}$ Moreover, controls have the expected sign. In particular, being employed or educated improves women's chances to carry more equal social norms, as well as mother's education, since it is a proxy for gender equality in the household. ${ }^{7}$ Age is also correlated with greater empowerment, as young girls are allowed less freedoms, but until a certain threshold, after which women return confined by traditional patriarchal norms.

In order to test whether our findings are driven by the use of Multiple Correspondence Analysis (MCA), we run the specifications using both Principal Component Analysis (PCA) and assigning equal weights. Table 3 shows the robustness of our results to the different weighting techniques.

It may be the case that estimates are valid for the composite index of the selfperceived role of women only for a fortuitous coincidence. To rule out this hypothesis, we test the robustness of our results by adopting a new index of gender norms. Specifically, we look at women's freedom of mobility (FMI) as an additional dimension of female empowerment (Table 4). The negative impact of return migration on gender equality at family level in Jordan is confirmed.

Table 5 introduces a further dimension of gender equality. Previous research has often regarded decision-making power within the family as a key aspect of female empowerment (Assaad, Nazier and Ramadan (2014)), focusing specifically on mar-

\footnotetext{
${ }^{6}$ As a robustness check, we run a simple Heckman selection, Table 15, where both the oil price variable and the shocks variable are found to be significant.

${ }^{7}$ Since women's employment status may be endogenous with our proxies of gender norms, specifications have also been undertaken without the employment variable, confirming the robustness of our findings. In addition, the level of education of the head of the household may also be important in establishing the extent of patriarchal discriminatory norms in place in the family. For this reason, we test the robustness of our results by including the education attainment of the head of the household as well. Results are consistent and are available from the authors.
} 
ried women and their bargaining power against other household members, usually husbands. This dimension is notably relevant for our paper since a strand of the literature pays particular attention to the effect of migration on the decision-making power of left-behind women. For instance, the recent work by Antman (2015) suggests that migrant husbands can hardly monitor the decision-making and resource allocation at home, thereby increasing left-behind wives' responsibilities and empowerment 8 However, although during the migration experience the absence of husbands can increase wives' responsibilities, this may be merely due to a change in household composition and not to a real transfer of positive gender norms. Most men may take back their patriarchal roles when they return back home (De Haas and Van Rooij (2010)), or even stream disciminatory gender norms, as suggested by our previous results. In order to test this hypothesis, we restrict the sample to only married women, and check whether those whose husbands are returnees have a negative impact of their decision-making power. Interestingly, estimates suggest the consistency of our previous findings, namely a transfer of discriminatory norms against women from return migration.

As a robustness check, we use single variables rather than composite indices. We examine several variables to capture our three types of indicators. Women were asked about their opinions as follows: 1) "Do you think women should get leadership positions in the society"; 2) "Can you go to the doctor for treatment without permission"; 3) "Can you visit a relative, friend or neighbour without permission"; 4) "In your family, do you usually have the final say in making large household purchases"; 5) "In your family, do you usually have the final say in taking the children to the doctor." As Table 16 in the Appendix shows, women in households where there are returnees are more likely to experience negative impact for all outcomes compared to women in households with no migration experience.9

\footnotetext{
${ }^{8}$ Spouse strategic responses to changes in monitoring have been confirmed by Ashraf (2009). Exploiting a randomized experiment in the Philippines, Ashraf finds that spousal control affects the decision-making power within the household.

${ }^{9}$ In addition, we also test the robustness of our findings to a different matching age for the real price of crude oil in the selection into emigration equation. Specifically, we associate to each individual in our sample the real price of crude oil at the age of 24 , which is the standard age for
} 
Summing up, we consistently find a negative impact of return migration on gender norms in Jordan. According to our hypothesis, returnees bring back home gender norms assimilated during their stay at receiving countries. Hence, to understand why the relationship between returnees and gender norms in Jordan seems to be negative, we need to focus on destinations and their gender norms. As previously mentioned, we restricted our analysis to migration towards the Arab region. Gender norms in Arab countries are overall discriminatory against women. A 2010 Freedom House report argues that women throughout the Middle East continue to face systematic discrimination in both laws and social customs Kelly (2010). According to the same report, political and civil unrest in some regions have even hindered women's condition over the last decade. For example, gender-based violence in Iraq worsened women's livelihoods by forcing them to stay home, away from education and employment.

However, even within the Arab region, countries have different degrees of discriminatory social norms against women. We exploit this heterogeneity in gender inequality by defining countries on the basis of their degree of conservatism. In order to proxy for the underlying gender norms in practice in each country, we make use of the 2007 CIRI Human Rights Data Project, which includes two indices measuring the political and social rights that women have in each country (Cingranelli and Richards (2010) $) \sqrt{10}$ Clearly, these rights can be interpreted as opportunities open to women rather than female outcomes (which is instead the case for other cross-country gender indices, such as the Global Gender Gap by WEF or the Gender Inequality Index by UNDP, including educational and employment dimensions as well). We therefore calculate the average of the two CIRI political and social indices, and distinguish destination countries between those having lower average

the end of university education in Jordan. This may be an alternative age at which the average Jordanian enters in the labour market, and hence faces the choice between working within the country or migrating abroad. Table 18 in Appendix suggests again the strong robustness of our results.

${ }^{10}$ Data are from 2007 since the indicator on women's social rights has been collected only in that year, but it is instead key for our analysis, as it measures several social norms such as women's right to equal inheritance, right to participate in social, cultural, and community activities, right to enter into marriage on a basis of equality with men, and so forth. 
values than Jordan and those with similar or greater values ${ }^{11}$

Regardless of the weighting technique adopted and controlling for both selections into emigration and return migration, estimates confirm that, whilst migrants towards countries with similar level of discrimination do not matter, having a returnee from more conservative countries drives our finding of a significant and negative impact of return migration on the self-perceived role of women (Table 6). Results are similar using the Freedom of Mobility Index (FMI) or the Decision Making Power Index (DMPI) (see Tables 7 and 8 respectively). This suggests that the impact of international migration on discriminatory social institutions depends on the level of gender inequality in destination countries.

\subsection{Return migration and gender outcomes}

Our results so far show that return migration fuels the gender gap. In particular, conservative and very traditional views regarding women are perpetuated through migration. As shown, those gender norms are captured not only through female perceptions of their own roles, but also in their freedom of mobility and their decision making. In order for us to capture further the extent to which return migration affect gender inequalities, we examine several women's outcomes.

We use the same empirical strategy as before where we estimate multi-equation models in which we control for emigration and return migration to study the impact of return migration on our outcome of interest.

$$
\begin{gathered}
F_{i o}=\alpha_{0}+\alpha_{1} R_{i}+\alpha_{2} V_{i}+\epsilon_{i} \\
M_{k}=\beta_{0}+\beta_{1} O_{k}+\beta_{2} Z_{k}+\mu_{k}
\end{gathered}
$$

\footnotetext{
${ }^{11}$ Countries with more conservative gender norms than Jordan include: Bahrain, Egypt, Kuwait, Lebanon, Lybia, Palestine, Qatar, Saudi Arabia, United Arab Emirates, and Yemen. Conversely, countries with similar gender norms than Jordan are: Algeria, Iraq, Morocco, Oman, Sudan, Syria, and Tunisia.
} 


$$
R_{k}=\gamma_{0}+\gamma_{1} S_{k}+\gamma_{2} C_{k}+n_{k}
$$

$F_{i o}$ is the gender outcome of interest detailed below where $o=1, \ldots, 4 . V_{i}$ are controls capturing the women's and households characteristics. As before, in equation 6. $M_{k}$ is the probability of individual $k$ being an emigrant, whilst $O_{k}$ is the international oil price variable. Controls $Z_{i}$ for the potential migrants and their household. In the return migration equation $7, R_{k}$ is the probability of being a return migrant, $S_{k}$ represents the shock variable, and $C_{i}$ is controls related to the migrant.

The first outcome of interest, $o=1$, is female employment. Although women are on average highly educated, with more than 40 percent having at least a secondary degree, only 14 percent of them is formally employed (see Table 1). One of the main causes of this paradox lies in the existence of gender norms which set what is deemed acceptable for women, limiting their employment at full capacity. On the one hand, female limited geographical mobility restrict women's job opportunities, but also employers' perception and low demand for female workers create further hurdles to women's access to the labour market. Indeed, in a recent randomized control trial in Jordan, Groh et al. (2012) found that employers often express explicit preferences for male workers, since women may experience problems interacting with customers due to culture.

In order to test the hypothesis of a link between return migration and female employment, we focus on female labour force participation which is preferred to the simple probability of employment since most women in Jordan tend to work for the public sector, and are willing to queue and stay unemployed for a while waiting a governmental job (Assaad, Hendy and Yassine (2014)). We also restrict our sample to unmarried women, as wives do not usually work in Jordanian society, and keeping them in the analysis would bias our estimates 12 In order to control

\footnotetext{
${ }^{12}$ As stressed by Assaad, Hendy and Yassine (2014), discrimination against married women take place directly at the hiring level, since employers often assume that wives' responsibilities would prevent them from committment at work, and hence they prefer to hire men and unmarried women. As a consequence, women themselves tend to stop looking for a job after marriage and withdraw from the labor force.
} 
for household income/wealth, we create an asset index, constructed as exogenously as possible by aggregating information about housing characteristics. Inspired by Filmer and Pritchett (2001), our asset index includes overall area and ownership of the accommodation, whether there is piped water, a bathroom, a fireplace/heater, water heating and whether the house is attached to the public sewage ${ }^{13}$ Once controlling for both selections into emigration and return migration, Table 9 indeed shows that having a returnee in the household reduces the likelihood of unmarried women to be in the labour force (column 3). Distinguishing between returnees from more conservative destination countries (column 4) and returnees from countries with similar gender norms than Jordan (column 5) suggests the transfer of opposite norms.

Women's education is a key strategy for reducing poverty and contributing to economic development by improving the productive capacities of the labor force. Our second outcome, $o=2$, relates therefore to female education. We look at how women's education interacts with return migration. Although Jordan has overall relatively high female education levels, international migration may still affect the probability of a girl dropping out from school if her father has been exposed to highly discriminatory gender norms during his migration experience. Remarkably, in our dataset we are able to identify the likelihood of daughters leaving education for family reasons due to customs and traditions.

Controlling again for wealth, Table 10 suggests that returnees are more likely than non-migrant fathers to make their daughters drop-out from school due to patricarchal gender norms. In particular, column 4 shows that findings are driven by returnees from more conservative Arab destinations (whilst the coefficient of return migration from countries with similar gender norms than Jordan in column 5 is not significant).

A further socioeconomic dimension which is deeply interlocked with social norms is women's fertility (Munshi and Myaux (2006)). While at the aggregate level high fertility rates are detrimental to the economy, since they reduce available resources

\footnotetext{
${ }^{13}$ The JLMPS database also provides a proxy for household wealth, which is measured by aggregating several housing characteristics and appliances. Results are also robust to this alternative indicator of wealth and are available from the authors.
} 
and jobs opportunities, at household level having numerous children is often associated with lower female empowerment, as mothers may not get further education or employment due to the large family size. The dependent variable in columns 1 to 3 of Table 11 is hence the probability of having at least one child $(o=3)$.

Results suggest that wives with a returnee husband are more likely to be mothers. Column 4 shows the relationship between returnee husbands and the number of children $(o=4)$, which is instead a choice of the couple. A concern for this analysis may be that returnees have higher incomes and therefore can afford having more children. For this reasons, all presented specifications include our constructed asset index. All the results are robust to the inclusion of the different wealth indicators (ours and that provided directly by the JLMPS) and to the exclusion of a wealth proxy ${ }^{14}$ Remarkably, results are driven again by returnees from more conservative countries (column 5), while returnees from countries with similar discriminatory levels than Jordan do not appear to significantly modify left-behind members' social norms. To sum up, our findings show that return migration affect not only perception but also women's outcomes.

We conclude by quantifying the impact of return migration on the selected female outcomes by calculating their predicted values for women with a returnee household member and women with no migration experience in the family. Table 12 shows that having a returnee in the family decreases women's probability of being in the labour force by 11 percent. Similarly, daughters who dropped out of school for traditional values are six times more likely to have a returnee father than a non-migrant father. Finally, wives of returnees are more likely not only to be mothers, but also to have one more child compared to wives of stayers, controlling for income.

\section{Conclusions}

This paper studies the impact of return migration on the transfer of gender norms. We focus on the case of Jordan where female labour force participation is among the

\footnotetext{
${ }^{14}$ Results are available from the authors.
} 
lowest in the world and where more than one household out of 10 have a returnee family member from other Arab countries. We construct several composite indices of female empowerment capturing (i) the role of women, (ii) freedom of mobility and (iii) decision making power, and use various weighting techniques.

Controlling for both selection into emigration and selection into return migration, our estimates show that women with a returnee in the household are more likely to have internalized discriminatory gender norms than women in households with no migration experience. Similar findings are obtained when examining women's freedom of mobility and decision-making power. Our results are also robust to the use of different weighting techniques for the construction of the female empowerment composite index, such as Multiple Correspondence Analysis (MCA), Principal Component Analysis (PCA) and equal weights.

Interestingly, we find that results are driven by returnees from more conservative Arab countries, which indeed bear great level of gender inequalities. This confirms our initial hypothesis of a transfer of gender norms through return migration. However, in this case return migration does not promote better institutions at home through the transfer of norms from destination countries, but encourages greater discrimination against women if the returnee has lived in a high discriminatory destination. Furthermore our results show that the impact of return migration goes beyond perception and affect negatively women's outcomes.

From policy perspective, the main hurdle for Jordan is to change social norms which are unfavorable towards women by promoting policies that enhance female position in Jordanian society and aim at eradicating discriminatory social institutions, encouraging female entrepreneurial skills and access to finance, and removing the barriers to the full exploitation of women's economic potential. 


\section{Bibliography}

Alesina, Alberto, Paola Giuliano, and Nathan Nunn. 2013. "On the Origins of Gender Roles: Women and the Plough." The Quarterly Journal of Economics, 128(2): 469-530.

Antman, Francisca M. 2015. "Gender discrimination in the allocation of migrant household resources." Journal of Population Economics, 28(3): 565-592.

Ashraf, Nava. 2009. "Spousal control and intra-household decision making: An experimental study in the Philippines." American Economic Review, 1245-1277.

Assaad, Ragui, Rana Hendy, and Chaimaa Yassine. 2014. "Gender and the Jordanian labor market." The Jordanian Labour Market in the New Millennium, 172.

Assaad, R., Hanan Nazier, and Racha Ramadan. 2014. "Individual and households determinants of women empowerment: Application to the case of Egypt." ERF Working Paper No. $86 \%$.

Batista, Catia, and Pedro C Vicente. 2011. "Do migrants improve governance at home? Evidence from a voting experiment." The World Bank Economic Review, 25(1): $77-104$.

Beaman, Lori, Raghabendra Chattopadhyay, Esther Duflo, Rohini Pande, and Petia Topalova. 2009. "Powerful Women: Does Exposure Reduce Bias?" The Quarterly Journal of Economics, 124(4): 1497-1540.

Beine, Michel, Frédéric Docquier, and Maurice Schiff. 2013. "International Migration, Transfers of Norms and Home Country Fertility." Canadian Journal of Economics, 46(4): 1406-1430.

Bertoli, Simone, and Francesca Marchetta. 2015. "Bringing it all back home: Return migration and fertility choices." World Development, 65: 27-40. 
Booysen, Frikkie, Servaas Van Der Berg, Ronelle Burger, Michael von Maltitz, and Gideon du Rand. 2008. "Using an asset index to assess trends in poverty in seven sub-Saharan African countries." World Development, 36(6): 11131130.

Chauvet, Lisa, and Marion Mercier. 2014. "Do return migrants transfer political norms to their origin country? Evidence from Mali." Journal of Comparative Economics, 42(3): 630-651.

Cingranelli, David L, and David L Richards. 2010. "The Cingranelli and Richards (CIRI) human rights data project." Human Rights Quarterly, 32(2): 401424.

David, Anda, and Mohamed Ali Marouani. 2013. "The Labor MobilityEmployment Nexus: A General Equilibrium Analysis of Jordan." ERF Working Paper No. 824.

De Haas, Hein, and Aleida Van Rooij. 2010. "Migration as emancipation? The impact of internal and international migration on the position of women left behind in rural Morocco." Oxford Development Studies, 38(1): 43-62.

Duflo, Esther. 2012. "Women empowerment and economic development." Journal of Economic Literature, 50(4): 1051-79.

Ferrant, Gaëlle. 2014. "The Multidimensional Gender Inequalities Index (MGII): A Descriptive Analysis of Gender Inequalities Using MCA." Social Indicators Research, 115(2): 653-690.

Ferrant, Gaëlle, and Michele Tuccio. 2015. "South-South migration and discrimination against women in social institutions: A two-way relationship." World Development, 72: 240-254.

Field, Erica, Seema Jayachandran, and Rohini Pande. 2010. "Do traditional institutions constrain female entrepreneurship? A field experiment on business training in India." American Economic Review, 125-129. 
Filmer, Deon, and Lant H Pritchett. 2001. "Estimating wealth effects without expenditure data - Or tears: An application to educational enrollments in states of India." Demography, 38(1): 115-132.

Groh, Matthew, Nandini Krishnan, David McKenzie, and Tara Vishwanath. 2012. "Soft skills or hard cash? The impact of training and wage subsidy programs on female youth employment in Jordan." World Bank, Washington, DC.

Kelly, Sanja. 2010. Women's Rights in the Middle East and North Africa. New York: Freedom House.

Lodigiani, Elisabetta, and Sara Salomone. 2012. "Migration-induced Transfers of Norms. The case of Female Political Empowerment." IRES Discussion Papers 2012-1.

McKenzie, David, Caroline Theoharides, and Dean Yang. 2014. "Distortions in the International Migrant Labor Market: Evidence from Filipino Migration and Wage Responses to Destination Country Economic Shocks." American Economic Journal: Applied Economics, 6(2): 49-75.

Meyersson, Erik. 2014. "Islamic rule and the empowerment of the poor and pious." Econometrica, 82(1): 229-269.

Munshi, Kaivan, and Jacques Myaux. 2006. "Social norms and the fertility transition." Journal of Development Economics, 80(1): 1-38.

OECD. 2014. "Social Institutions \& Gender Index - Jordan." Available at: genderindex.org/sites/default/files/datasheets/JO.pdf (accessed 17 April 2015).

Omar Mahmoud, Toman, Hillel Rapoport, Andreas Steinmayr, and Christoph Trebesch. 2014. "The effect of labor migration on the diffusion of democracy: Evidence from a former Soviet Republic." IZA Discussion Paper No. 7980 . 
Roodman, David. 2011. "Estimating fully observed recursive mixed-process models with cmp." Stata Journal, 11(2): 159-206.

Spilimbergo, Antonio. 2009. "Democracy and foreign education." American Economic Review, 528-543.

Wahba, Jackline. 2014. "Immigration, emigration, and the labor market in Jordan." The Jordanian Labour Market in the New Millennium, 172.

Wahba, Jackline. 2015. "Selection, selection, selection: The impact of return migration." Journal of Population Economics, Forthcoming.

Wahba, Jackline, and Yves Zenou. 2012. "Out of sight, out of mind: Migration, entrepreneurship and social capital." Regional Science and Urban Economics, 42(5): 890-903.

World Bank. 2005. The economic advancement of women in Jordan: A country gender assessment. Washington, DC: The World Bank.

Xu, Zhimei, and Dilip Ratha. 2008. Migration and remittances factbook 2008. Washington, DC: The World Bank. 
Table 1: Characteristics of women in returnee and non-migrant households

\begin{tabular}{lccl}
\hline & Without migrant & With returnee & t-Test \\
\hline Employment status & 0.14 & 0.14 & $(0.24)$ \\
Less than basic education & 0.22 & 0.18 & $(3.08)^{* *}$ \\
Basic education & 0.37 & 0.32 & $(3.48)^{* * *}$ \\
Secondary education & 0.19 & 0.24 & $(-3.96)^{* * *}$ \\
Post-secondary education & 0.22 & 0.26 & $(-3.19)^{* *}$ \\
Married & 0.56 & 0.57 & $(-0.13)$ \\
Consanguinity & 0.22 & 0.19 & $(2.46)^{*}$ \\
Rural areas & 0.35 & 0.10 & $(17.82)^{* * *}$ \\
Age & 30.97 & 32.99 & $(-5.52)^{* * *}$ \\
Age squared & 10.94 & 12.64 & $(-6.66)^{* * *}$ \\
Children & 0.92 & 0.92 & $(-0.19)$ \\
Mother's education & 1.83 & 2.31 & $(-12.44)^{* * *}$ \\
\hline$N$ & 5350 & 1344 & \\
\hline
\end{tabular}

Notes. Source: JLMPS, 2010. 
Figure 1: Emigrants by year and real oil price

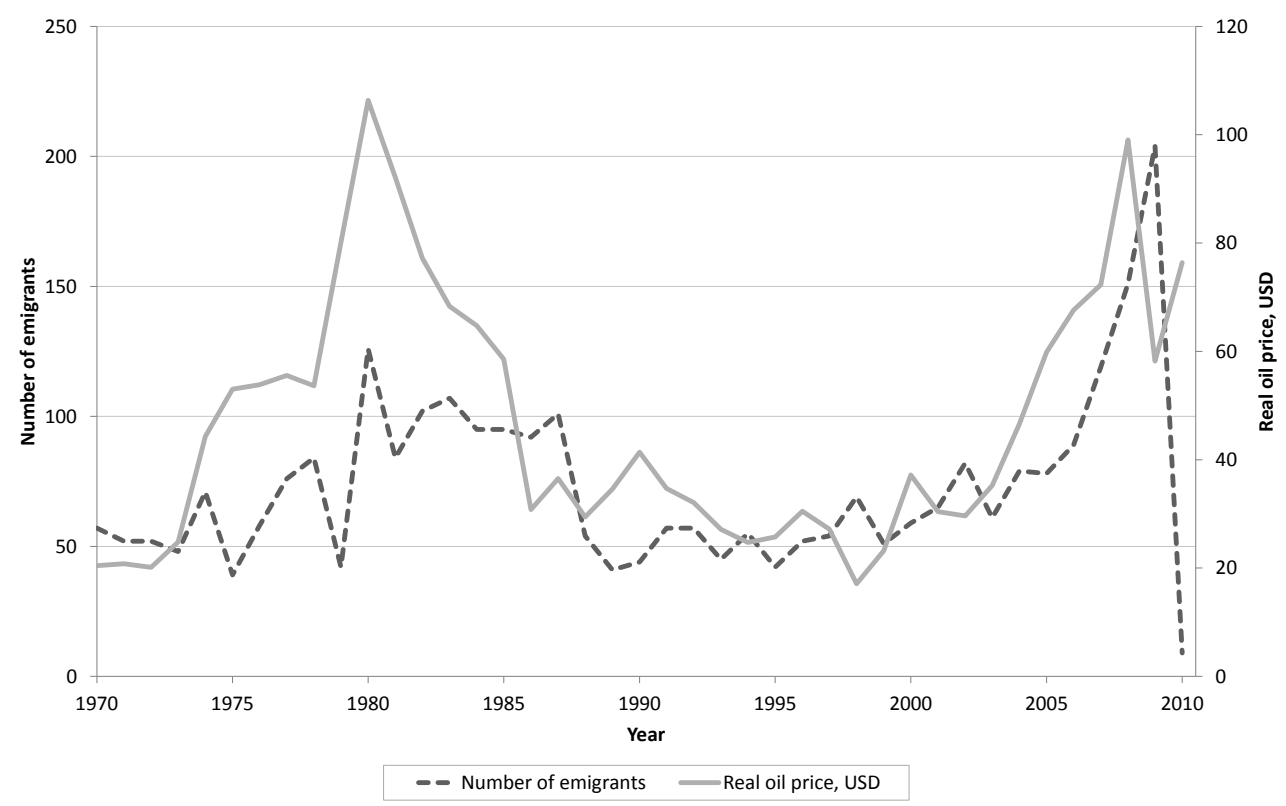


Table 2: Return migration and the Role of Women Index (RWI)

\begin{tabular}{|c|c|c|c|}
\hline & (1) & $(2)$ & (3) \\
\hline \multicolumn{4}{|l|}{$R W I$} \\
\hline Return migrant & $\begin{array}{l}-0.005 \\
(0.005)\end{array}$ & $\begin{array}{l}-0.051 \\
(0.037)\end{array}$ & $\begin{array}{c}-0.062 \\
(0.030)^{* *}\end{array}$ \\
\hline Employment status & $\begin{array}{c}0.020 \\
(0.004)^{* * *}\end{array}$ & $\begin{array}{c}0.023 \\
(0.005)^{* * *}\end{array}$ & $\begin{array}{c}0.022 \\
(0.005)^{* * *}\end{array}$ \\
\hline Basic education & $\begin{array}{c}0.011 \\
(0.006)\end{array}$ & $\begin{array}{c}0.015 \\
(0.007)^{* *}\end{array}$ & $\begin{array}{c}0.017 \\
(0.007)^{* *}\end{array}$ \\
\hline Secondary education & $\begin{array}{c}0.020 \\
(0.008)^{* * *}\end{array}$ & $\begin{array}{c}0.029 \\
(0.010)^{* * *}\end{array}$ & $\begin{array}{c}0.029 \\
(0.009)^{* * *}\end{array}$ \\
\hline Post-secondary education & $\begin{array}{c}0.028 \\
(0.006)^{* * *}\end{array}$ & $\begin{array}{c}0.039 \\
(0.011)^{* * *}\end{array}$ & $\begin{array}{c}0.050 \\
(0.013)^{* * *}\end{array}$ \\
\hline Married & $\begin{array}{l}-0.008 \\
(0.009)\end{array}$ & $\begin{array}{c}-0.008 \\
(0.009)\end{array}$ & $\begin{array}{l}-0.008 \\
(0.009)\end{array}$ \\
\hline Consanguineous marriage & $\begin{array}{c}0.002 \\
(0.004)\end{array}$ & $\begin{array}{c}0.002 \\
(0.004)\end{array}$ & $\begin{array}{c}0.002 \\
(0.004)\end{array}$ \\
\hline Rural area & $\begin{array}{c}0.002 \\
(0.004)\end{array}$ & $\begin{array}{c}0.002 \\
(0.004)\end{array}$ & $\begin{array}{c}0.003 \\
(0.004)\end{array}$ \\
\hline Age & $\begin{array}{c}0.003 \\
(0.001)^{* *}\end{array}$ & $\begin{array}{c}0.003 \\
(0.001)^{* *}\end{array}$ & $\begin{array}{c}0.003 \\
(0.002)^{* *}\end{array}$ \\
\hline Age squared & $\begin{array}{l}-0.003 \\
(0.002)\end{array}$ & $\begin{array}{l}-0.003 \\
(0.002)\end{array}$ & $\begin{array}{c}-0.004 \\
(0.002)^{*}\end{array}$ \\
\hline Children & $\begin{array}{c}0.011 \\
(0.008)\end{array}$ & $\begin{array}{c}0.012 \\
(0.008)\end{array}$ & $\begin{array}{c}0.012 \\
(0.008)\end{array}$ \\
\hline Mother's education & $\begin{array}{c}0.004 \\
(0.002)^{* *} \\
\end{array}$ & $\begin{array}{c}0.004 \\
(0.002)^{* *} \\
\end{array}$ & $\begin{array}{c}0.004 \\
(0.002)^{* *}\end{array}$ \\
\hline \multicolumn{4}{|l|}{ Probability of Emigration } \\
\hline Oil price & & $\begin{array}{c}0.002 \\
(0.000)^{* * *}\end{array}$ & $\begin{array}{c}0.001 \\
(0.000)^{* * *} \\
\end{array}$ \\
\hline \multicolumn{4}{|c|}{ Probability of Return Migration } \\
\hline Shocks & & & $\begin{array}{c}0.148 \\
(0.009)^{* * *} \\
\end{array}$ \\
\hline sigma_1 & & $\begin{array}{c}-0.835 \\
(0.005)^{* * *}\end{array}$ & $\begin{array}{c}-0.874 \\
(0.006)^{* * *}\end{array}$ \\
\hline sigma_2 & & & $\begin{array}{c}-1.100 \\
(0.014)^{* * *}\end{array}$ \\
\hline rho_12 & & $\begin{array}{c}0.207 \\
(0.161)\end{array}$ & $\begin{array}{c}0.222 \\
(0.122)^{*}\end{array}$ \\
\hline rho_13 & & & $\begin{array}{c}0.223 \\
(0.103)^{* *}\end{array}$ \\
\hline rho_23 & & & $\begin{array}{c}1.388 \\
(0.037)^{* * *}\end{array}$ \\
\hline
\end{tabular}

Notes. (I) All specifications are weighted by the sampling weights provided in the dataset, with robust standard errors. (II) Data source: JLMPS, 2010. 
Table 3: The Role of Women Index using different weighting techniques

\begin{tabular}{lccc}
\hline & $\mathbf{( 1 )}$ & $\mathbf{( 2 )}$ & $\mathbf{( 3 )}$ \\
\hline RWI & $\mathbf{m c a}$ & $\mathbf{p c a}$ & equal \\
Return migrant & -0.062 & -0.085 & -0.089 \\
& $(0.030)^{* *}$ & $(0.033)^{* *}$ & $(0.038)^{* *}$ \\
\hline Probability of Emigration & & & \\
Oil price & 0.001 & 0.001 & 0.001 \\
& $(0.000)^{* * *}$ & $(0.000)^{* * *}$ & $(0.000)^{* * *}$ \\
\hline Probability of Return Migration & & & \\
Shocks & 0.148 & 0.148 & 0.148 \\
& $(0.009)^{* * *}$ & $(0.009)^{* * *}$ & $(0.009)^{* * *}$ \\
\hline sigma_1 & -0.874 & -0.874 & -0.874 \\
& $(0.006)^{* * *}$ & $(0.006)^{* * *}$ & $(0.006)^{* * *}$ \\
sigma_2 & -1.100 & -1.100 & -1.100 \\
& $(0.014)^{* * *}$ & $(0.014)^{* * *}$ & $(0.014)^{* * *}$ \\
rho_12 & 0.222 & 0.262 & 0.218 \\
& $(0.122)^{*}$ & $(0.120)^{* *}$ & $(0.107)^{* *}$ \\
rho_13 & 0.223 & 0.252 & 0.210 \\
& $(0.103)^{* *}$ & $(0.102)^{* *}$ & $(0.094)^{* *}$ \\
rho_23 & 1.388 & 1.388 & 1.388 \\
& $(0.037)^{* * *}$ & $(0.037)^{* * *}$ & $(0.037)^{* * *}$ \\
\hline
\end{tabular}

Notes. (I) All specifications are weighted by the sampling weights provided in the dataset, with robust standard errors. (II) Data source: JLMPS, 2010. 
Table 4: Return migration and the Freedom of Mobility Index (FMI)

\begin{tabular}{lccc}
\hline & $\mathbf{( 1 )}$ & $\mathbf{( 2 )}$ & $\mathbf{( 3 )}$ \\
\hline FMI & $\mathbf{m c a}$ & $\mathbf{p c a}$ & equal \\
Return migrant & -0.131 & -0.140 & -0.131 \\
& $(0.045)^{* * *}$ & $(0.043)^{* * *}$ & $(0.045)^{* * *}$ \\
\hline Probability of Emigration & & & \\
Oil price & 0.001 & 0.001 & 0.001 \\
& $(0.000)^{* * *}$ & $(0.000)^{* * *}$ & $(0.000)^{* * *}$ \\
\hline Probability of Return Migration & & & \\
Shocks & 0.148 & 0.148 & 0.148 \\
& $(0.009)^{* * *}$ & $(0.009)^{* * *}$ & $(0.009)^{* * *}$ \\
\hline sigma_1 & -0.899 & -0.899 & -0.899 \\
& $(0.006)^{* * *}$ & $(0.006)^{* * *}$ & $(0.006)^{* * *}$ \\
sigma_2 & -1.138 & -1.138 & -1.138 \\
& $(0.015)^{* * *}$ & $(0.015)^{* * *}$ & $(0.015)^{* * *}$ \\
rho_12 & 0.304 & 0.336 & 0.303 \\
& $(0.095)^{* * *}$ & $(0.095)^{* * *}$ & $(0.095)^{* * *}$ \\
rho_13 & 0.282 & 0.318 & 0.282 \\
& $(0.092)^{* * *}$ & $(0.092)^{* * *}$ & $(0.092)^{* * *}$ \\
rho_23 & 1.387 & 1.387 & 1.387 \\
& $(0.037)^{* * *}$ & $(0.037)^{* * *}$ & $(0.037)^{* * *}$ \\
\hline
\end{tabular}

Notes. (I) All specifications are weighted by the sampling weights provided in the dataset, with robust standard errors. (II) Data source: JLMPS, 2010. 
Table 5: Return migration and the Decision Making Power Index (DMPI)

\begin{tabular}{lccc}
\hline & $\mathbf{( 1 )}$ & $\mathbf{( 2 )}$ & $\mathbf{( 3 )}$ \\
\hline DMPI & $\mathbf{m c a}$ & $\boldsymbol{p c a}$ & $\boldsymbol{e q u a l}$ \\
Return migrant & -0.153 & -0.151 & -0.148 \\
& $(0.082)^{*}$ & $(0.066)^{* *}$ & $(0.088)^{*}$ \\
\hline Probability of Emigration & & & \\
Oil price & 0.001 & 0.001 & 0.001 \\
& $(0.000)^{* * *}$ & $(0.000)^{* * *}$ & $(0.000)^{* * *}$ \\
\hline Probability of Return Migration & & & \\
Shocks & 0.001 & 0.001 & 0.001 \\
& $(0.000)^{* * *}$ & $(0.000)^{* * *}$ & $(0.000)^{* * *}$ \\
\hline sigma_1 & -0.953 & -0.953 & -0.952 \\
& $(0.006)^{* * *}$ & $(0.006)^{* * *}$ & $(0.006)^{* * *}$ \\
sigma_2 & -1.207 & -1.207 & -1.207 \\
& $(0.015)^{* * *}$ & $(0.015)^{* * *}$ & $(0.015)^{* * *}$ \\
rho_12 & 0.243 & 0.246 & 0.238 \\
& $(0.149)$ & $(0.139)^{*}$ & $(0.155)$ \\
rho_13 & 0.237 & 0.263 & 0.232 \\
& $(0.135)^{*}$ & $(0.133)^{* *}$ & $(0.140)^{*}$ \\
rho_23 & 1.388 & 1.388 & 1.388 \\
& $(0.037)^{* * *}$ & $(0.037)^{* * *}$ & $(0.037)^{* * *}$ \\
\hline
\end{tabular}

Notes. (I) All specifications are weighted by the sampling weights provided in the dataset, with robust standard errors. (II) Data source: JLMPS, 2010. 
Table 6: Return migration by destination and the Role of Women Index (RWI)

\begin{tabular}{|c|c|c|c|c|c|c|}
\hline & (1) & $(2)$ & (3) & (4) & (5) & (6) \\
\hline & \multicolumn{3}{|c|}{ More conservative destinations } & \multicolumn{3}{|c|}{ Conservative destinations } \\
\hline & $m c a$ & pca & equal & $m c a$ & pca & equal \\
\hline \multirow[t]{2}{*}{ Return migrant } & -0.077 & -0.103 & -0.107 & 0.153 & 0.147 & 0.121 \\
\hline & $(0.031)^{* *}$ & $(0.035)^{* * *}$ & $(0.040)^{* * *}$ & $(0.088)^{*}$ & $(0.111)$ & $(0.103)$ \\
\hline \multicolumn{7}{|c|}{ Probability of Emigration } \\
\hline \multirow[t]{2}{*}{ Oil price } & 0.001 & 0.001 & 0.001 & 0.001 & 0.001 & 0.001 \\
\hline & $(0.000)^{* * *}$ & $(0.000)^{* * *}$ & $(0.000)^{* * *}$ & $(0.000)^{* * *}$ & $(0.000)^{* * *}$ & $(0.000)^{* * *}$ \\
\hline \multicolumn{7}{|c|}{ Probability of Return Migration } \\
\hline \multirow[t]{2}{*}{ Shocks } & 0.148 & 0.148 & 0.148 & 0.148 & 0.148 & 0.148 \\
\hline & $(0.009)^{* * *}$ & $(0.009)^{* * *}$ & $(0.009)^{* * *}$ & $(0.009)^{* * *}$ & $(0.009)^{* * *}$ & $(0.009)^{* * *}$ \\
\hline \multirow[t]{2}{*}{ sigma_1 } & -0.874 & -0.874 & -0.874 & -0.874 & -0.874 & -0.874 \\
\hline & $(0.006)^{* * *}$ & $(0.006)^{* * *}$ & $(0.006)^{* * *}$ & $(0.006)^{* * *}$ & $(0.006)^{* * *}$ & $(0.006)^{* * *}$ \\
\hline \multirow[t]{2}{*}{ sigma_2 } & -1.100 & -1.100 & -1.100 & -1.100 & -1.100 & -1.100 \\
\hline & $(0.014) * * *$ & $(0.014)^{* * *}$ & $(0.014) * * *$ & $(0.014)^{* * *}$ & $(0.014) * * *$ & $(0.014)^{* * *}$ \\
\hline \multirow[t]{2}{*}{ rho_12 } & 0.284 & 0.332 & 0.272 & -0.661 & -0.614 & -0.362 \\
\hline & $(0.128)^{* *}$ & $(0.123)^{* * *}$ & $(0.111)^{* *}$ & $(0.331)^{* *}$ & $(0.369)^{*}$ & $(0.265)$ \\
\hline \multirow[t]{2}{*}{ rho_13 } & 0.279 & 0.307 & 0.255 & -0.485 & -0.427 & -0.295 \\
\hline & $(0.107)^{* * *}$ & $(0.104)^{* * *}$ & $(0.097)^{* * *}$ & $(0.212)^{* *}$ & $(0.248)^{*}$ & $(0.230)$ \\
\hline \multirow[t]{2}{*}{ rho_23 } & 1.387 & 1.387 & 1.388 & 1.387 & 1.387 & 1.387 \\
\hline & $(0.037)^{* * *}$ & $(0.037)^{* * *}$ & $(0.037)^{* * *}$ & $(0.037) * * *$ & $(0.037)^{* * *}$ & $(0.037)^{* * *}$ \\
\hline
\end{tabular}

Notes. (I) All specifications are weighted by the sampling weights provided in the dataset, with robust standard errors.

(II) Data source: JLMPS, 2010. 
Table 7: Return migration by destination and the Freedom of Mobility Index (FMI)

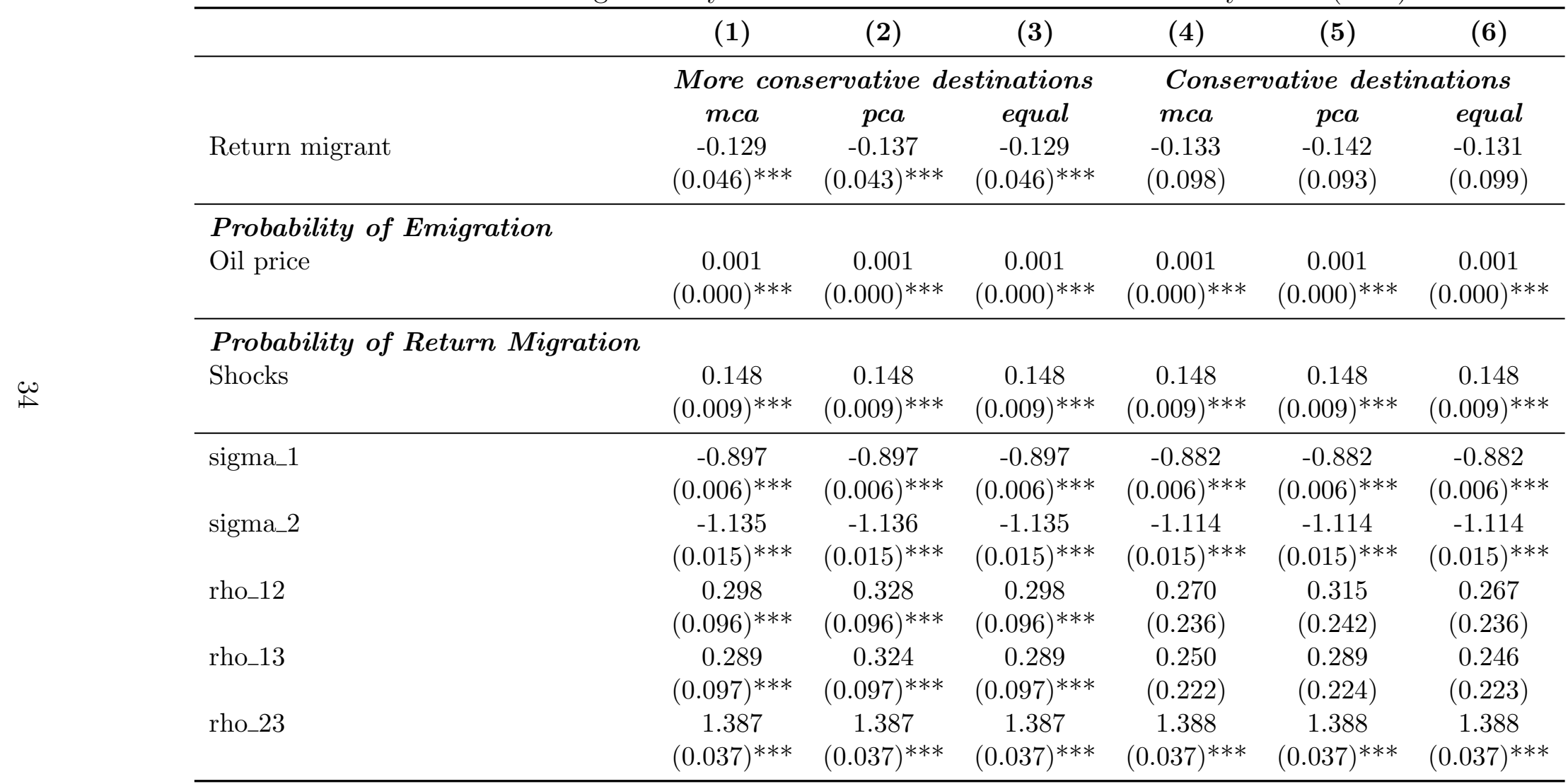

Notes. (I) All specifications are weighted by the sampling weights provided in the dataset, with robust standard errors.

(II) Data source: JLMPS, 2010. 
Table 8: Return migration by destination and the Decision Making Power Index (DMPI)

\begin{tabular}{lcccccc}
\hline & $(\mathbf{1})$ & $\mathbf{( 2 )}$ & $\mathbf{( 3 )}$ & $\mathbf{( 4 )}$ & $\mathbf{( 5 )}$ & $\mathbf{( 6 )}$ \\
\hline & More conservative & destinations & \multicolumn{2}{c}{ Conservative destinations } \\
& $\mathbf{m c a}$ & $\boldsymbol{p c a}$ & equal & mca & pca & equal \\
Return migrant & -0.168 & -0.151 & -0.163 & 0.098 & 0.008 & 0.086 \\
& $(0.087)^{*}$ & $(0.067)^{* *}$ & $(0.093)^{*}$ & $(0.223)$ & $(0.207)$ & $(0.233)$ \\
\hline Probability of Emigration & & & & & & \\
Oil price & 0.001 & 0.001 & 0.001 & 0.001 & 0.001 & 0.001 \\
& $(0.000)^{* * *}$ & $(0.000)^{* * *}$ & $(0.000)^{* * *}$ & $(0.000)^{* * *}$ & $(0.000)^{* * *}$ & $(0.000)^{* * *}$ \\
\hline Probability of Return Migration & & & & & & \\
Shocks & 0.148 & 0.148 & 0.148 & 0.148 & 0.148 & 0.148 \\
& $(0.009)^{* * *}$ & $(0.009)^{* * *}$ & $(0.009)^{* * *}$ & $(0.009)^{* * *}$ & $(0.009)^{* * *}$ & $(0.009)^{* * *}$ \\
\hline sigma_1 & -0.946 & -0.946 & -0.946 & -0.916 & -0.916 & -0.916 \\
& $(0.006)^{* * *}$ & $(0.006)^{* * *}$ & $(0.006)^{* * *}$ & $(0.006)^{* * *}$ & $(0.006)^{* * *}$ & $(0.006)^{* * *}$ \\
sigma_2 & -1.194 & -1.194 & -1.194 & -1.147 & -1.146 & -1.147 \\
& $(0.015)^{* * *}$ & $(0.015)^{* * *}$ & $(0.015)^{* * *}$ & $(0.014)^{* * *}$ & $(0.014)^{* * *}$ & $(0.014)^{* * *}$ \\
rho_12 & 0.254 & 0.229 & 0.247 & -0.042 & 0.036 & -0.007 \\
& $(0.156)$ & $(0.141)$ & $(0.163)$ & $(0.397)$ & $(0.429)$ & $(0.408)$ \\
rho_13 & 0.273 & 0.265 & 0.269 & -0.178 & -0.024 & -0.159 \\
& $(0.144)^{*}$ & $(0.140)^{*}$ & $(0.149)^{*}$ & $(0.353)$ & $(0.393)$ & $(0.359)$ \\
rho_23 & 1.387 & 1.387 & 1.388 & 1.387 & 1.387 & 1.387 \\
& $(0.037)^{* * *}$ & $(0.037)^{* * *}$ & $(0.037)^{* * *}$ & $(0.037)^{* * *}$ & $(0.037)^{* * *}$ & $(0.037)^{* * *}$ \\
\hline
\end{tabular}

Notes. (I) All specifications are weighted by the sampling weights provided in the dataset, with robust standard errors.

(II) Data source: JLMPS, 2010. 
Table 9: Return migration and female labour force participation

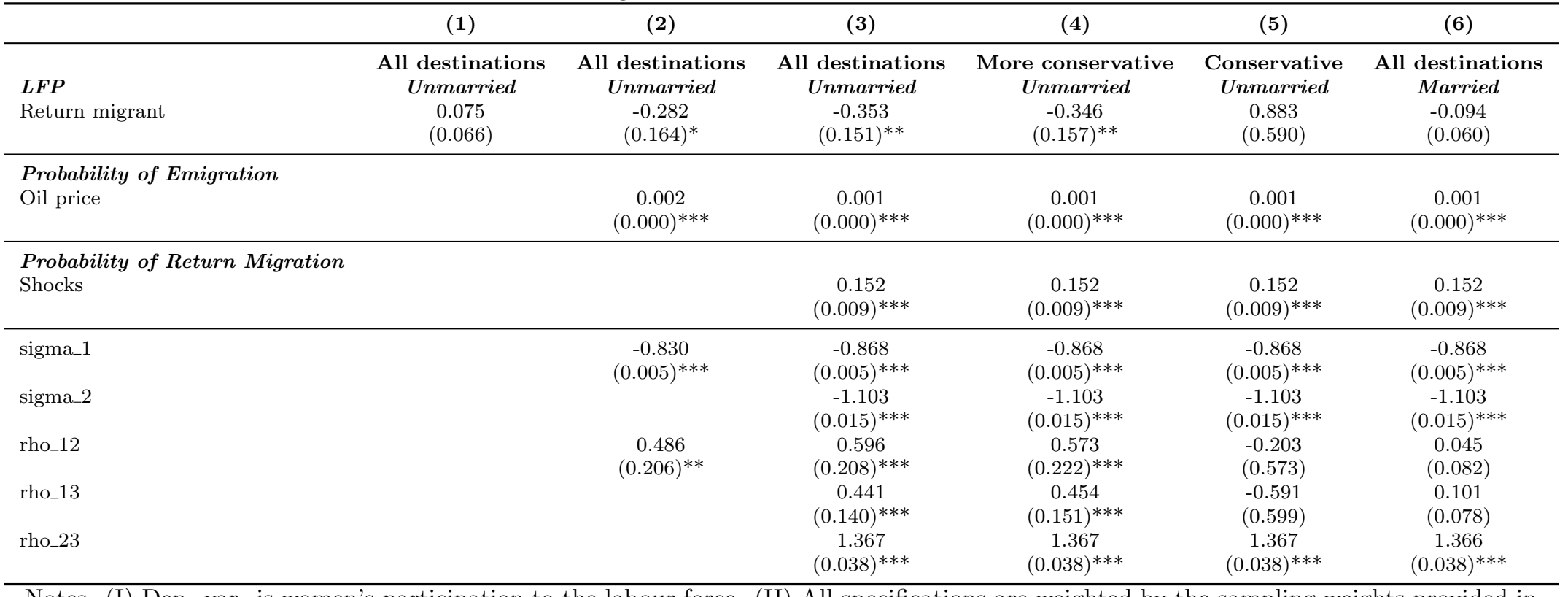

Notes. (I) Dep. var. is women's participation to the labour force. (II) All specifications are weighted by the sampling weights provided in the dataset, with robust standard errors. (III) Data source: JLMPS, 2010. 
Table 10: Return migration and daughters' dropout from education

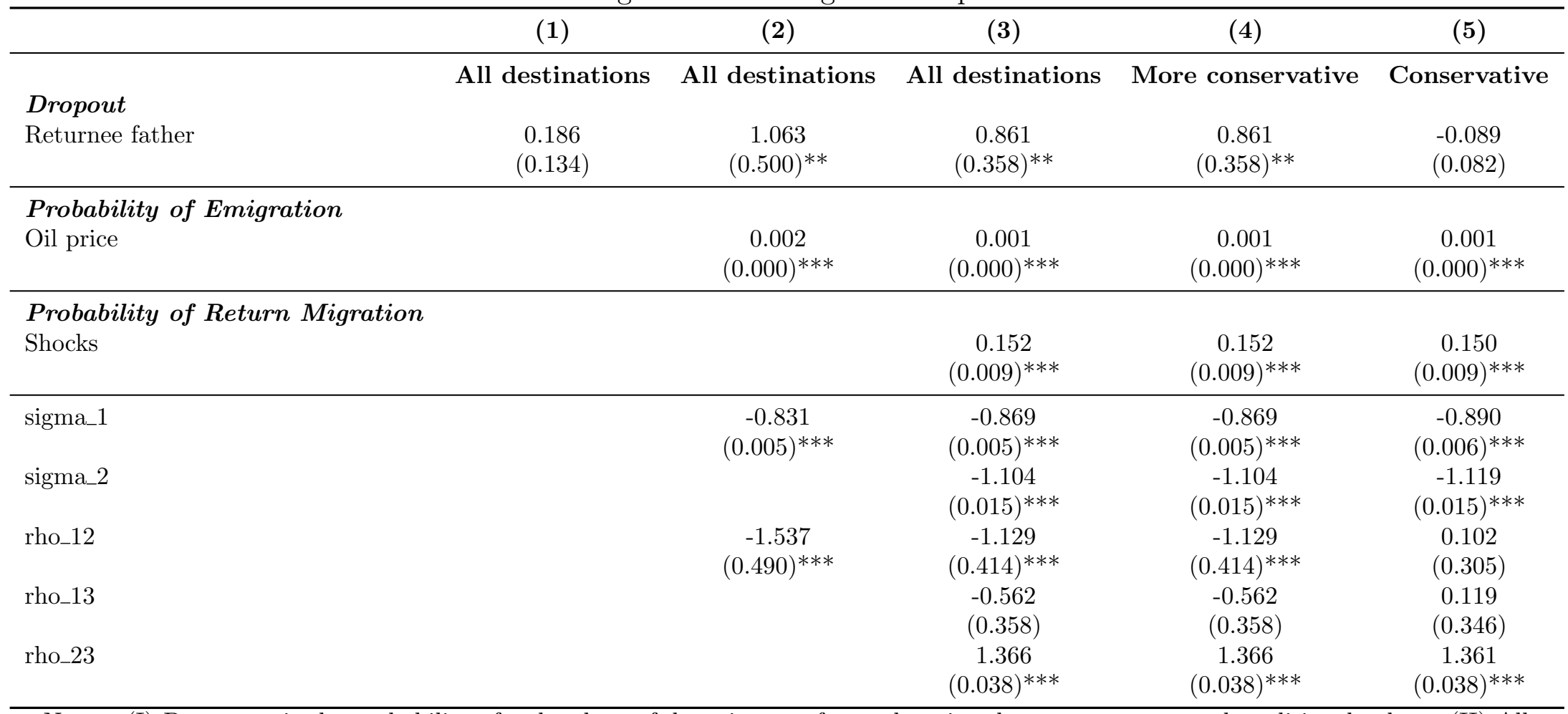

Notes. (I) Dep. var. is the probability of a daughter of dropping out from education due to customary and traditional values. (II) All specifications are weighted by the sampling weights provided in the dataset, with robust standard errors. (III) Data source: JLMPS, 2010. 
Table 11: Return migration and wives' fertility

(1)

(2)

(3)

(4)

(5)

(6)

\begin{tabular}{|c|c|c|c|c|c|c|}
\hline & (1) & (2) & (3) & (4) & (5) & (6) \\
\hline \multicolumn{7}{|c|}{ More conservative } \\
\hline Returnee husband & $\begin{array}{l}-0.006 \\
(0.013)\end{array}$ & $\begin{array}{c}0.497 \\
(0.050)^{* * *}\end{array}$ & $\begin{array}{c}0.370 \\
(0.072)^{* * *}\end{array}$ & $\begin{array}{c}0.798 \\
(0.404)^{* *}\end{array}$ & $\begin{array}{c}0.892 \\
(0.419)^{* *}\end{array}$ & $\begin{array}{c}1.090 \\
(1.148)\end{array}$ \\
\hline \multicolumn{7}{|c|}{ Probability of Emigration } \\
\hline Oil price & & $\begin{array}{c}0.002 \\
(0.000)^{* * *}\end{array}$ & $\begin{array}{c}0.001 \\
(0.000)^{* * *}\end{array}$ & $\begin{array}{c}0.001 \\
(0.000)^{* * *}\end{array}$ & $\begin{array}{c}0.001 \\
(0.000)^{* * *}\end{array}$ & $\begin{array}{c}0.001 \\
(0.000)^{* * *}\end{array}$ \\
\hline \multicolumn{7}{|c|}{ Probability of Return Migration } \\
\hline Shocks & & & $\begin{array}{c}0.147 \\
(0.009)^{* * *} \\
\end{array}$ & $\begin{array}{c}0.148 \\
(0.009)^{* * *} \\
\end{array}$ & $\begin{array}{c}0.148 \\
(0.009)^{* * *} \\
\end{array}$ & $\begin{array}{c}0.148 \\
(0.009)^{* * *} \\
\end{array}$ \\
\hline \multirow[t]{2}{*}{ sigma_1 } & & -0.832 & -0.874 & -0.874 & -0.874 & -0.874 \\
\hline & & $(0.005)^{* * *}$ & $(0.005)^{* * *}$ & $(0.006)^{* * *}$ & $(0.006)^{* * *}$ & $(0.006)^{* * *}$ \\
\hline \multirow[t]{2}{*}{ sigma_2 } & & & -1.100 & -1.100 & -1.100 & -1.100 \\
\hline & & & $(0.015)^{* * *}$ & $(0.014)^{* * *}$ & $(0.014)^{* * *}$ & $(0.014)^{* * *}$ \\
\hline \multirow[t]{2}{*}{ rho_12 } & & -0.970 & -0.792 & -0.199 & -0.235 & -0.206 \\
\hline & & $(0.083)^{* * *}$ & $(0.116)^{* * *}$ & $(0.106)^{*}$ & $(0.108)^{* *}$ & $(0.265)$ \\
\hline \multirow{2}{*}{ rho_13 } & & & -0.525 & -0.217 & -0.240 & -0.258 \\
\hline & & & $(0.086)^{* * *}$ & $(0.101)^{* *}$ & $(0.104)^{* *}$ & $(0.297)$ \\
\hline \multirow[t]{2}{*}{ rho_23 } & & & 1.383 & 1.387 & 1.387 & 1.387 \\
\hline & & & $(0.037)^{* * *}$ & $(0.037)^{* * *}$ & $(0.037)^{* * *}$ & $(0.037)^{* * *}$ \\
\hline
\end{tabular}

Notes. (I) Dep. var. in columns 1 to 3 is the probability of having at least one child, whilst dep. var in columns 4 to 6 is the number of children. (II) All specifications are weighted by the sampling weights provided in the dataset, with robust standard errors. (III) Data source: JLMPS, 2010. 
Table 12: Average predicted values

\begin{tabular}{lcccc}
\hline & With returnee & Without migrant & Difference (\%) & P-value \\
\hline Probability of being in the labour force & -0.111 & 0.246 & -1.45 & 0.00 \\
Probability of dropping out from education & 0.565 & -0.114 & -5.93 & 0.00 \\
Probability of having at least one child & 1.169 & 0.819 & 0.43 & 0.00 \\
Number of children & 4.792 & 3.835 & 0.25 & 0.00 \\
\hline
\end{tabular}

Notes. (I) P-value reports the results of a t test of Ho: Return migration=Non-migrants. (II) Values are weighted by the sampling weights provided in the dataset. (III) Data source: JLMPS, 2010. 


\section{Appendix}

Table 13: Variables included in RWI and respective weights

\begin{tabular}{|c|c|c|c|c|}
\hline Variable & Categories & EQUAL & PCA & MCA \\
\hline \multirow[t]{2}{*}{ Place of a woman should not only be the house, she should be allowed to work } & Agree & 0.1 & 0.3949 & 0.079 \\
\hline & Disagree & & & -0.812 \\
\hline \multirow[t]{2}{*}{ A husband should help the working mother in taking care of the children } & Agree & 0.1 & 0.3855 & 0.055 \\
\hline & Disagree & & & -1.109 \\
\hline \multirow[t]{2}{*}{ A husband should help the working wife in housework } & Agree & 0.1 & 0.3390 & 0.084 \\
\hline & Disagree & & & -0.560 \\
\hline \multirow[t]{2}{*}{ Female education should be to get jobs, not only to become good wives/mothers } & Agree & 0.1 & 0.1112 & 0.063 \\
\hline & Disagree & & & -0.080 \\
\hline \multirow{2}{*}{ The woman working outside home can be a good mother } & Agree & 0.1 & 0.2489 & 0.069 \\
\hline & Disagree & & & -0.370 \\
\hline \multirow[t]{2}{*}{ Women should work in order to be financially independent } & Agree & 0.1 & 0.1643 & 0.088 \\
\hline & Disagree & & & -0.126 \\
\hline \multirow{2}{*}{ Female work doesn't contradict with ability to build good relationship with husband } & Agree & 0.1 & 0.2481 & 0.092 \\
\hline & Disagree & & & -0.276 \\
\hline \multirow[t]{2}{*}{ Women should get leadership positions in the society } & Agree & 0.1 & 0.3071 & 0.089 \\
\hline & Disagree & & & -0.437 \\
\hline \multirow[t]{2}{*}{ I do not mind if boys and girls get the same level of education } & Agree & 0.1 & 0.4028 & 0.026 \\
\hline & Disagree & & & -2.547 \\
\hline \multirow[t]{2}{*}{ Boys and girls should be treated equally } & Agree & 0.1 & 0.4014 & 0.023 \\
\hline & Disagree & & & -2.856 \\
\hline
\end{tabular}

Notes. Source: JLMPS, 2010. 
Table 14: Variables included in FMI and respective weights

\begin{tabular}{|c|c|c|c|c|}
\hline Variable & Categories & EQUAL & PCA & MCA \\
\hline You can go to the market without permission & $\begin{array}{c}\text { Agree } \\
\text { Disagree }\end{array}$ & 0.25 & 0.5009 & $\begin{array}{c}0.186 \\
-3.522\end{array}$ \\
\hline You can go to the doctor for treatment without permission & $\begin{array}{c}\text { Agree } \\
\text { Disagree }\end{array}$ & 0.25 & 0.5140 & $\begin{array}{c}0.192 \\
-3.590\end{array}$ \\
\hline You can go to take one of the children to the doctor without permission & $\begin{array}{c}\text { Agree } \\
\text { Disagree }\end{array}$ & 0.25 & 0.4927 & $\begin{array}{c}0.197 \\
-3.217\end{array}$ \\
\hline You can visit a relative, friend or neighbour without permission & $\begin{array}{c}\text { Agree } \\
\text { Disagree }\end{array}$ & 0.25 & 0.4921 & $\begin{array}{c}0.186 \\
-3.408\end{array}$ \\
\hline
\end{tabular}


Table 15: Variables included in DMPI and respective weights

\begin{tabular}{|c|c|c|c|c|}
\hline Variable & Categories & EQUAL & PCA & MCA \\
\hline \multirow[t]{2}{*}{ In your family you usually have the final say in making large household purchases } & Agree & 0.11 & 0.3193 & 1.174 \\
\hline & Disagree & & & -0.115 \\
\hline \multirow[t]{2}{*}{ In your family you usually have the final say in making household purchases for daily needs } & Agree & 0.11 & 0.3495 & 0.881 \\
\hline & Disagree & & & -0.183 \\
\hline \multirow[t]{2}{*}{ In your family you usually have the final say in visiting family, friends or relatives } & Agree & 0.11 & 0.3108 & 0.856 \\
\hline & Disagree & & & -0.149 \\
\hline \multirow[t]{2}{*}{ In your family you usually have the final say in choosing what food should be cooked each day } & Agree & 0.11 & 0.3083 & 0.405 \\
\hline & Disagree & & & -0.310 \\
\hline \multirow[t]{2}{*}{ In your family you usually have the final say in getting medical treatment or advice for yourself } & Agree & 0.11 & 0.3489 & 0.466 \\
\hline & Disagree & & & -0.345 \\
\hline \multirow{2}{*}{ In your family you usually have the final say in buying clothes for yourself } & Agree & 0.11 & 0.2831 & 0.248 \\
\hline & Disagree & & & -0.427 \\
\hline \multirow[t]{2}{*}{ In your family you usually have the final say in taking the children to the doctor } & Agree & 0.11 & 0.3874 & 0.836 \\
\hline & Disagree & & & -0.237 \\
\hline \multirow[t]{2}{*}{ In your family you usually have the final say in sending the children to school } & Agree & 0.11 & 0.2954 & 0.775 \\
\hline & Disagree & & & -0.149 \\
\hline \multirow[t]{2}{*}{ In your family you usually have the final say in buying clothes for the children } & Agree & 0.11 & 0.3808 & 0.698 \\
\hline & Disagree & & & -0.275 \\
\hline
\end{tabular}

Notes. Source: JLMPS, 2010. 
Table 16: Robustness check - Heckman selection

\begin{tabular}{lcc}
\hline & $(1)$ & $(2)$ \\
\hline \multirow{2}{*}{ Oil price } & Probability of Return Migration & Probability of Emigration \\
& & 0.007 \\
Shocks & 0.104 & $(12.55)^{* * *}$ \\
Mills & $(7.36)^{* * *}$ & \\
& 0.618 \\
$\chi^{2}(18)=1156.26$ & $(12.65)^{* * *}$ \\
Observations & Prob $>\chi^{2}=0.000$ \\
\hline
\end{tabular}

Notes. Source: JLMPS, 2010. 
Table 17: Robustness check - Single variables

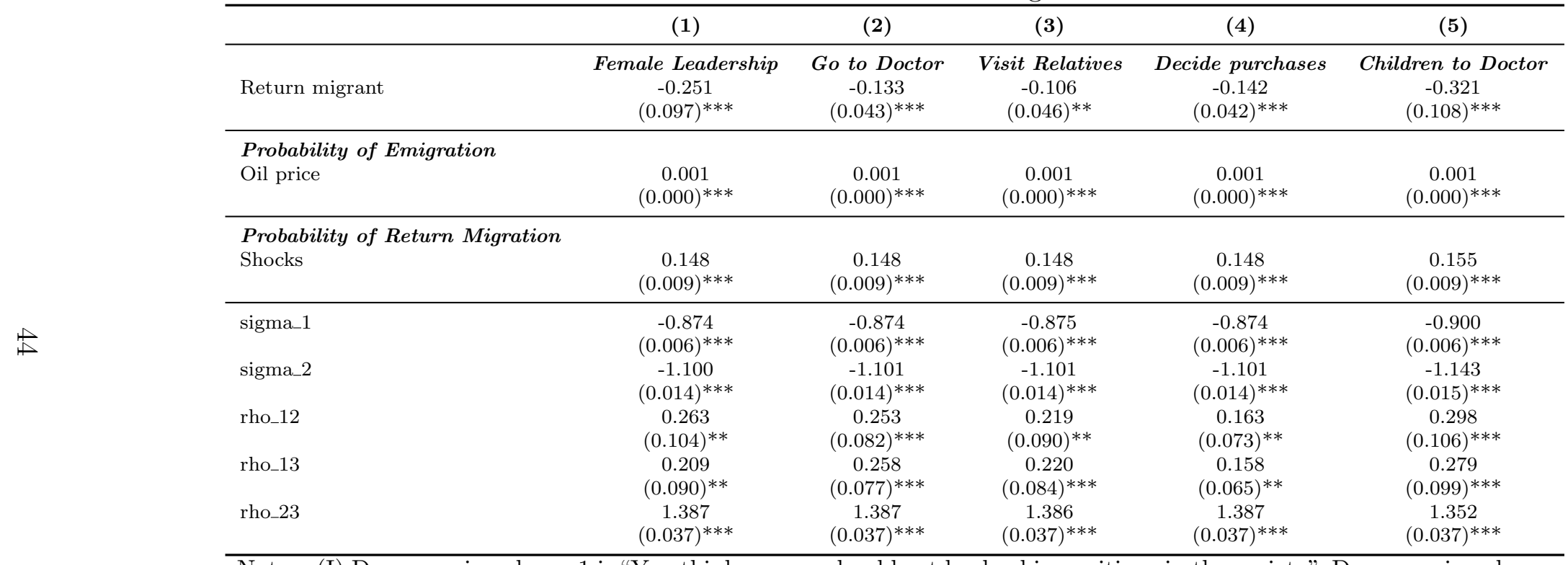

Notes. (I) Dep. var. in column 1 is "You think women should get leadership positions in the society"; Dep. var. in column 2 is "You can go to the doctor for treatment without permission"; Dep. var. in column 3 is "You can visit a relative, friend or neighbour without permission"; Dep. var. in column 4 is "In your family you usually have the final say in making large household purchases"; Dep. var. in column 5 is "In your family you usually have the final say in taking the children to the doctor". (II) All specifications are weighted by the sampling weights provided in the dataset, with robust standard errors. (III) Data source: JLMPS, 2010. 
Table 18: Robustness check - Reference year for oil price

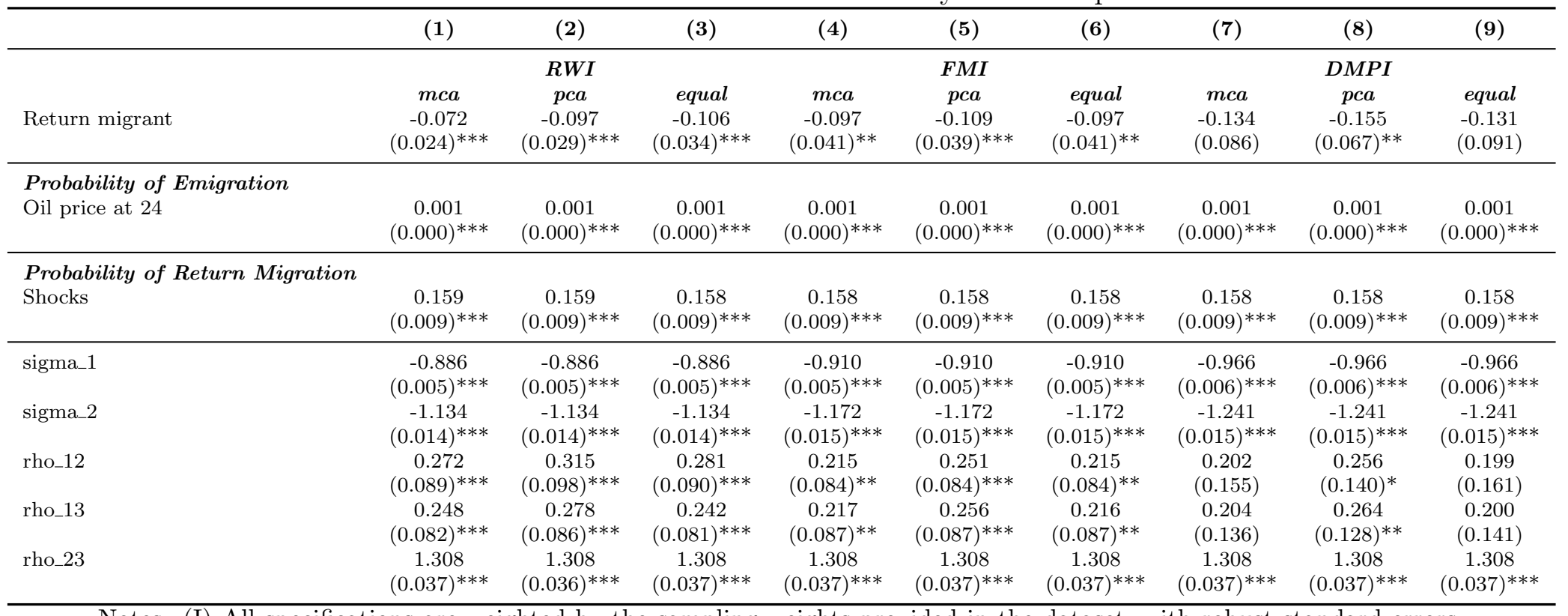

Notes. (I) All specifications are weighted by the sampling weights provided in the dataset, with robust standard errors.

(II) Data source: JLMPS, 2010. 